\title{
Criteria of Chagas Disease Cure
}

\author{
J Romeu Cançado \\ Cadeira de Terapêutica Clínica, Universidade Federal de Minas Gerais, Caixa Postal 486, 31270-901 Belo \\ Horizonte, MG, Brasil
}

Key words: Chagas disease - cure - treatment - Trypanosoma cruzi

The investigation of the rational etiological treatment of Chagas disease, through controlled clinical trials, only began around half a century after the discovery of the disease. This resulted from a meeting held in Rio de Janeiro, in 1962, between a number of Brazilian researchers and representatives from the pharmaceutical industry (Anais 1962).

Two facts were then known: (1) nitrofuran compounds are active against Trypanosoma cruzi: (2) long course administration of nitrofurazone prevents the development of experimental infection in mouse.

At that meeting, we had the opportunity of discussing methods of evaluation of therapeutic efficacy.

We discarded clinical criteria, due to the slow natural evolution of the disease. Furthermore, since the main objective of specific therapy is the eradication of the causative organism, the criterion of cure should be the proof of the elimination of $T$. cruzi, demonstrated in practice by the post-therapeutic consistent negative parasitological and serological tests, at that time, respectively, xenodiagnosis (XD) and complement fixation (CF).

In the years following the landmark 1962 meeting, we examined, at the University Hospital and private practice, in Belo Horizonte, MG, Brasil, 2,405 Chagas disease patients, 47 with the acute and 2,358 with various chronic forms (Table I).

We performed several controlled clinical trials, with nitrofurazone, l-furaltadone, nifurtimox, benznidazole, ketoconazole, among other drugs. In addition, new diagnostic tests were introduced: hemoculture (HC), quantitative indirect immunofluorescence test (IF), quantitative indirect hemagglutination test (HA) and complement mediated lysis (CoML).

Rua dos Otoni, 927, conj. 602, Belo Horizonte, MG, Brasil. Sponsorship from Fundação Carlos Chagas de Pesquisa Médica, Belo Horizonte, MG, Brasil.

Fax: +55-31-273. 4234.

Received 9 June 1999

Accepted 9 August 1999

\section{IMMUNE RESPONSE}

T. cruzi induces in humans an acute phase infection, with patent parasitemia, which is followed by a life-long chronic phase, characterized by subpatent parasitemia and scarce tissue parasitism. It is thus evident that immunity to $T$. cruzi involves mechanisms that control the exponential growth of the parasites during the early phase of the disease as well as the sustained immune response during the chronic phase. The latter maintains the parasitemia at extremely low levels but is unable to eradicate the infection (Brener 1992) .

The importance of the role of this strong and sustained immune response in the cure process, irrespective of the chemotherapy being used, cannot be overestimated.

Specific antibodies IgM and IgG may be detected in the serum at the time of the first clinical manifestations of the acute phase, but the titers of IgM decline soon after this phase, becoming basal during the life-long chronic phase, when only high levels of IgG are found in the serum.

The titers of the antibodies are variable and do not correlate with the severity of the disease. Indeed, during the life-long chronic phase of human infection by $T$. cruzi, a strong humoral immune response consisting of different immunoglobulin types, prevails.

The disease may last for decades and there is no spontaneous cure.

The most common tests for detecting IgG are complement fixation (CF), indirect immunofluoscence (IF), indirect hemagglutination (HA) and the immunoenzymatic assay (ELISA).

\section{SENSITIVITY OF DIAGNOSTIC TESTS}

Table II displays the results of serological diagnostic tests and xenodiagnosis done repeatedly, during a period of one to five years, in twenty chronic chagasic patients treated with placebo. The high sensititvity of the serological tests, in contrast with the low sensitivity of $\mathrm{XD}$, is clearly evident. PARASITOLOGICAL AND SEROLOGICAL TESTS
AS MEANS TO ASSESS CURE

Our experience with the evaluation of efficiency of chemotherapy reveals an important difference 
TABLE I

Patients

\begin{tabular}{|c|c|c|}
\hline \multicolumn{2}{|c|}{ Patients examined $\quad(1960-1997)$} & 2,405 \\
\hline \multicolumn{2}{|c|}{$\begin{array}{l}\text { In the acute phase } \\
\text { contaminated by: }\end{array}$} & 47 \\
\hline triatomine & 37 & \\
\hline blood transfusion & 8 & \\
\hline laboratory accident & 2 & \\
\hline In the chronic phase & & 2,358 \\
\hline
\end{tabular}

between parasitological and serological tests (Cançado 1985, 1997, 1999).

Parasitological tests - In the long-standing chronic disease, negative results obtained with parasitological tests (xenodiagnosis and hemoculture), even when repeated many times over a long period, do not by themselves, without taking in account the results of serological tests, indicate parasitological cure, as they may reflect periods of absent or scarce parasitemia. Nevertheless, in patients with high parasitemia, as in recent chronic disease, they reflect drug activity. Parasitemia is reduced but the disease is not cured (Cançado 1985).

$\mathrm{HC}$ and XD are aleatory methods.

Serological tests - The detection of specific antibodies against components of $T$. cruzi is universally used for the diagnosis of the disease, since the introduction of the method by Guerreiro and Machado, in 1913. Positive results conclusively demonstrate Chagas disease.

Such tests must be the basis for the evaluation of drug efficacy against $T$. cruzi, since the only possibility of their becoming negative is the disappearance of the stimulus for specific antibody production: the parasite.

In short, positive parasitological tests prove the presence of the parasite, but are of low sensitivity, whereas positive serological tests offer indirect but very sensitive proof of parasite presence, especially when two or three different simultaneous tests are repeatedly positive.

Cure of the acute form is followed by serological tests becoming completely and consistently negative after a period of about 12 months. In chronic forms, for reason not well known, negative sero-conversion is slow, taking years to complete, requiring a long follow up to prove cure of chronic disease.

\section{COMPLEMENT MEDIATED LYSIS (COML) AND} CONVENTIONAL SEROLOGY (CS)

CoML detects lytic antibodies, which are recognized by epitopes present on the surface of liv- ing trypomastigotes, in contrast to CS, which detects antibodies that recognize epitopes present on the surface of fixed parasites, or parasite extracts. Hence, CoML and CS measure different responses.

With the aim of studying the value of CoML for the evaluation of the efficacy of chemotherapy, we participate in several studies in collaboration with researchers of the Centro de Pesquisa René RachouFiocruz, Belo Horizonte, where CoML was developed (Krettli \& Brener 1982). We provided the serum and clinical data from the patients we treated.

CoML is not a routine method because it requires careful management of living infective trypomastigotes, and it was employed only during a short period of our work.

Assuming that positive CoML indicates the presence of living trypomastigotes in the organism of the patient and, therefore, active infection, we went as for as to accept the absence of lytic antibodies as a criterion of cure, despite residual positive results obtained by CS (Galvão et al. 1993).

This conclusion, however, must be re-examined since post-therapy positive CS continues to reveal high antibodies titers, in 77 per cent of 113 treated chronic patients, followed up for more than six years (Cançado 1999).

As we have stated earlier (Krettli et al. 1982), cure of Chagas disease should be based not only on negative XD but also on the elimination of specific antibodies detectable with the CS and CoML tests.

A diagnostic test based on only one epitope, or a small set of epitopes, in a infection caused by such a complex parasite as T. cruzi, needs a further evaluation.

Negative CoML, by itself, is not a criterion of cure of Chagas disease, because absence of living trypomastigotes does not necessarily mean absence of active infection. The parasite may persist in the tissues, in the amastigote forms. Even circulating in the peripheral blood, these parasites would not stimulate the production of lytic antibodies, but could be the cause of the uniformely positive CS in the great majority of the treated patients with long standing Chagas disease.

Antigenic differences are recognized among the developmental stages of T. cruzi. Amastigote forms from tissue cultures are a more sensitive antigen than epimastigotes (Ferreira 1992).

\section{PATHOGENESIS OF CHAGAS DISEASE DEPENDS ON THE PARASITE}

Strongest piece of evidence that the parasite remains in the patient throughout the entire evolutive process of the disease is the reactivation of the infection following heart transplants in cases of terminal chronic chagasic cardiomyopathy, where the immunosupressive drugs used result in 
TABLE II

Serological and parasitological progression of 20 chronic chagasic patients treated with placebo

\begin{tabular}{|c|c|c|c|c|c|c|c|c|c|c|}
\hline \multirow[t]{2}{*}{ No. } & \multirow[t]{2}{*}{ Name } & \multirow[t]{2}{*}{$\begin{array}{l}\text { Age } \\
\text { (years) }\end{array}$} & \multirow[t]{2}{*}{ Sex } & \multirow[t]{2}{*}{$\begin{array}{l}\text { Clinical } \\
\text { form }\end{array}$} & \multirow[t]{2}{*}{$\begin{array}{l}\text { Follow up } \\
\text { (years) }\end{array}$} & \multicolumn{5}{|c|}{$\begin{array}{c}\text { No. of positive tests } \\
\text { No. of tests done }\end{array}$} \\
\hline & & & & & & CF & IF & HA & CoML & XD \\
\hline 01 & AMS & 63 & $\mathrm{M}$ & I & 1 & $\begin{array}{l}6 \\
6\end{array}$ & $\frac{6}{6}$ & $\begin{array}{l}6 \\
6\end{array}$ & & $\frac{0}{6}$ \\
\hline 02 & ACA & 51 & $\mathrm{~F}$ & $\mathrm{C} 1$ & 5 & $\frac{9}{9}$ & $\frac{9}{9}$ & $\begin{array}{l}3 \\
3\end{array}$ & $\begin{array}{l}5 \\
5\end{array}$ & \\
\hline 03 & AML & 32 & $\mathrm{~F}$ & $\mathrm{CD}$ & 3 & $\frac{25}{30}$ & $\frac{45}{45}$ & $\frac{44}{44}$ & & $\frac{3}{32}$ \\
\hline 04 & ARM & 42 & $\mathrm{~F}$ & I & 3 & $\begin{array}{l}6 \\
8\end{array}$ & $\frac{6}{8}$ & $\frac{1}{1}$ & $\begin{array}{l}7 \\
7\end{array}$ & $\frac{0}{1}$ \\
\hline 05 & $\mathrm{AMB}$ & 42 & $\mathrm{M}$ & $\mathrm{C} 2$ & 2 & $\frac{32}{33}$ & $\frac{33}{33}$ & $\frac{33}{33}$ & & $\frac{2}{26}$ \\
\hline 06 & DRL & 37 & $\mathrm{~F}$ & $\mathrm{C} 1$ & 2 & $\frac{8}{8}$ & $\frac{8}{8}$ & $\begin{array}{l}8 \\
8\end{array}$ & & $\frac{0}{7}$ \\
\hline 07 & DFF & 54 & $\mathrm{~F}$ & $\mathrm{C} 1$ & 1 & $\frac{5}{5}$ & $\frac{4}{4}$ & $\begin{array}{l}4 \\
4\end{array}$ & & \\
\hline 08 & ELP & 48 & $\mathrm{~F}$ & $\mathrm{C} 2$ & 2 & $\frac{18}{18}$ & $\frac{18}{18}$ & $\frac{18}{18}$ & & $\frac{1}{13}$ \\
\hline 09 & FSP & 38 & M & $\mathrm{C} 2$ & 2 & $\frac{35}{35}$ & $\frac{35}{35}$ & $\frac{35}{35}$ & & $\frac{3}{26}$ \\
\hline 10 & HLA & 32 & M & $\mathrm{C} 2$ & 3 & $\frac{25}{26}$ & $\frac{28}{28}$ & $\frac{28}{28}$ & & $\frac{5}{23}$ \\
\hline 11 & IERJ & 37 & $\mathrm{~F}$ & $\mathrm{C} 1$ & 1 & $\begin{array}{l}5 \\
6\end{array}$ & $\frac{6}{6}$ & $\begin{array}{l}1 \\
1\end{array}$ & $\begin{array}{l}5 \\
5\end{array}$ & $\frac{0}{1}$ \\
\hline 12 & IRS & 40 & $\mathrm{~F}$ & $\mathrm{C} 1$ & 4 & $\begin{array}{l}11 \\
13\end{array}$ & $\frac{12}{13}$ & $\begin{array}{l}2 \\
2\end{array}$ & $\frac{12}{12}$ & $\frac{0}{2}$ \\
\hline 13 & MHD & 15 & $\mathrm{~F}$ & $\mathrm{C} 1$ & 5 & $\frac{7}{7}$ & $\frac{7}{7}$ & $\begin{array}{l}7 \\
7\end{array}$ & & $\frac{6}{37}$ \\
\hline 14 & MJLD & 41 & $\mathrm{~F}$ & $\mathrm{C} 1$ & 1 & $\begin{array}{l}7 \\
8\end{array}$ & $\frac{6}{6}$ & $\begin{array}{l}4 \\
4\end{array}$ & $\begin{array}{l}1 \\
2\end{array}$ & \\
\hline 15 & MJR & 48 & $\mathrm{~F}$ & $\mathrm{C} 1$ & 5 & $\frac{22}{28}$ & $\frac{28}{28}$ & $\begin{array}{l}2 \\
2\end{array}$ & $\frac{19}{19}$ & \\
\hline 16 & MRD & 58 & $\mathrm{~F}$ & I & 2 & $\begin{array}{l}4 \\
4\end{array}$ & $\frac{4}{4}$ & & $\frac{2}{2}$ & \\
\hline 17 & MCU & 40 & M & $\mathrm{C} 1$ & 2 & $\frac{24}{26}$ & $\frac{28}{28}$ & $\frac{27}{27}$ & & $\frac{14}{28}$ \\
\hline 18 & NFR & 52 & $\mathrm{~F}$ & $\mathrm{C} 1$ & 3 & $\begin{array}{l}5 \\
7\end{array}$ & $\frac{7}{7}$ & & $\frac{1}{1}$ & \\
\hline 19 & OPS & 35 & M & $\mathrm{C} 2$ & 1 & $\frac{20}{23}$ & $\frac{22}{22}$ & $\frac{22}{22}$ & & $\frac{7}{21}$ \\
\hline 20 & VAC & 19 & M & $\begin{array}{c}\mathrm{C} 2 \\
\\
\mathrm{I}, 3 \\
\mathrm{C}, 16\end{array}$ & 1 & $\begin{array}{c}9 \\
9 \\
283 \\
309\end{array}$ & $\begin{array}{c}9 \\
9 \\
321 \\
324\end{array}$ & $\begin{array}{c}9 \\
9 \\
254 \\
254\end{array}$ & $\begin{array}{l}52 \\
53\end{array}$ & $\begin{array}{c}9 \\
10 \\
49 \\
234\end{array}$ \\
\hline & & & & $\mathrm{CD}, 1$ & & $91,5 \%$ & $99 \%$ & $100 \%$ & $98,1 \%$ & $21 \%$ \\
\hline
\end{tabular}


the reappearance of $T$. cruzi in blood and tissues. The majority of patients exhibit a return to the acute phase of the disease, with myocarditis in the transplanted heart.

Similarly, non chagasic patients submitted to immunosupressive regimes following a kidney transplant from sero-positive donors acquired the infection from the transplanted organ.

A further demonstration of the presence of the T. cruzi in chronic patients is the reactivation of the disease in Aids sufferers, with accompanying meningoencephalitis, myocarditis and other lesions, with high parasite burdens.

Immunosupression in chronic Chagas disease patients has revealed reservoirs of amastigotes in quite distinct organs and tissues, such as the central nervous system, the heart, the skin and the subcutaneous cellular tissue, the esophagus, the colon, the liver, the bone marrow, the kidney and others. The parasite, which apparently remained occult, disseminates when the strong and sustained immune response is suppressed.

In relation to the life-cycle of $T$. cruzi in vertebrate host, there are still some obscure and controversial points. Nevertheless, there is no evidence of the existence of resistant or latent forms. However, the finding, over the last 15 years, that immunosupression brings about reappearance of acute disease in long standing chronic patients justifies a revision of this matter.

\section{CONVENTIONAL SOROLOGY (CS) AS THE BASIS OF THE CRITERION OF CURE}

(1) Parasitological tests (XD e HC) are of poor sensitivity, slow (up to four months), only available in research institutions; (2) the tests which make up CS (CF, IF, HA), on the other hand, constitute the most sensitive method for the diagnosis of the disease; they are quick, inexpensive, easily done, generally employed and approved as trustworthy since the discovery of the disease. Only the complement fixation test requires a more refined technology and reagents, but IF and HA alone would be sufficient for the purpose in hand; (3) it is impossible for a negative CS test to occur with a positive parasitological test, except possibly in the case of immunosupression; (4) in acute disease CS is the universally accepted criterion of cure; (5) the experience gathered over the last 90 years in the diagnosis of chronic disease shows that the reactions done nowadays, with extracts of $T$. cruzi are sufficiently safe, when well standardized (Camargo 1992). In contrast, the use of purified and better defined antigens of $T$. cruzi or the direct use of the antigens, are far from clinical application; (6) CS was the method used to discover the prevalence of the disease in geographic areas; (7) all research on refined antigens, to be used for serological evaluation of chemotherapy, use as their gold standard to define cure the patients who presented consistent negative CS tests.

Positive CS conclusively demonstrate the presence of $T$. cruzi in the patient's tissues, i.e., Chagas disease.

Why it would lose this property after treatment?

To accept that the cured patient may maintain a positive CS after treatment, at the same titers as in the pre-therapeutic phase, would be a paradox: it would only require the patient to seek another physician, not to mention the history of treatment, for him to be diagnosed as chagasic.

\section{RESULTS OF SPECIFIC TREATMENT WITH BENZNIDAZOLE}

Today the only drug available in Brasil for the etiological treatment of Chagas disease is benznidazole.

In Table III, the conclusions of clinical trials we have done with this drug, in acute and chronic patients, are shown. They are based on CS (CF, IF and HA) results, following a long follow up, in comparison with the placebo treated group (Table I).

According to the results of CS, the patients were distributed among three classes (Table III): (1) cure, in case of the three reactions becoming completely and consistently negative; (2) failure, when the three reactions remained positive, with similar titers to the pre-therapeutic phase; (3) doubtful, when an oscillation in the results of at least two of the three tests occurred.

One of the most important findings shown in Table III is the considerable difference in the percentage of cure between acute and chronic patients.

Why does chemotherapy cure around three

TABLE III

Results of the etiologig treatment of chagas disease with benznidazole

\begin{tabular}{lccccc}
\hline Clinical form & No. of patients & Cure & Failure & Doubtful & $\begin{array}{c}\text { Follow up } \\
\text { (years) }\end{array}$ \\
\hline Acute & 21 & $16-76 \%$ & $5-24 \%$ & 13 to 21 \\
Chronic & 113 & $9-8 \%$ & $87-77 \%$ & $17-15 \%$ & 6 to 18 \\
\hline
\end{tabular}

During the early chronic disease (children and adolescent) the results are close to those obtained with the acute disease. 
quarters $(76 \%)$ of the acute patients while it fails in the same fraction of those with long standing chronic disease?

There is no satisfactory explanation for this phenomenon, which remains an open field of investigation.

\section{ACKNOWLEDGMENTS}

To the colleagues from the University of Minas Gerais and the Centro de Pesquisas René Rachou, for the permanent and unconcerned support. To Dr Andrew JG Simpson, for the review of the English language.

\section{REFERENCES}

Anais da reunião de debates sobre a doença de Chagas. Rio de Janeiro, Brasil, 19 a 21 de março de 1962. Rev Goiana Med (Supl.): 1-300.

Brener Z 1992. Immune response and immunopathology in T. cruzi infection, p. 31-47. In S Wendel, Z Brener, ME Camargo \& A Rassi (eds), Chagas Disease, its Impact on Transfusion and Clinical Medicine, ISBT, São Paulo.

Camargo ME 1992. An appraisal of Chagas disease serodiagnosis, p.165-178. In S Wendel, Z Brener, ME Camargo \& A Rassi (eds), Chagas Disease its Impact on Transfusion and Clinical Medicine, ISBT, São Paulo.
Cançado JR 1985. Tratamento específico, p. 327-355. In JR Cançado \& M Chuster (eds), Cardiopátia Chagásica, Fundação Carlos Chagas, Belo Horizonte.

Cançado JR 1997. Terapêutica específica, p. 323-351. In JC Pinto Dias \& JR Coura, (eds), Clínica e Terapeutica da Doença de Chagas, Fiocruz, Rio de Janeiro.

Cançado JR 1999. Tratamento etiológico da doença de Chagas pelo benznidazole. In Z Brener \& Z Andrade (eds), Trypanosoma cruzi e Doença de Chagas, $2^{\mathrm{a}}$ edição, Guanabara Koogan, Rio de Janeiro (in press).

Ferreira AW 1992. Tests for Chagas disease serodiagnosis, p. 179-193. In S Wendel, Z Brener, ME Camargo \& A Rassi (eds), Chagas Disease: its Impact on Transfusion and Clinical Medicine, ISBT, São Paulo.

Galvão LMC, Nunes RMB, Cançado JR, Brener Z, Krettli AU 1993. Lytic antibody titre as a mean of assessing cure after treatment of Chagas disease: a ten year follow up study. Trans R Soc Trop Med Hyg 87: 220-223.

Krettli AU, Brener Z 1982. Resistance against Trypanosoma cruzi associated to anti-living trypomastigotes antibodies. J Immunol 128: 2009-2012.

Krettli, Cançado JR, Brener Z 1982. Effect of specific chemotherapy on the levels of lytic antibodies in Chagas disease. Trans R Soc Trop Med Hyg 76: 334340 . 